\title{
Evaluation of Rainfall Measurements from the WXT510 Sensor for Use in the Oklahoma City Micronet
}

\author{
Jeffrey B. Basara ${ }^{*}$, Bradley G. Illston, Thomas E. Winning Jr. and Christopher A. Fiebrich
}

Oklahoma Climatological Survey, University of Oklahoma, USA

\begin{abstract}
A network of 40 real-time, automated atmospheric monitoring stations was deployed in Oklahoma City and officially commissioned on 8 November 2008: the Oklahoma City Micronet (OKCNET). The Oklahoma City Micronet includes 36 stations mounted on traffic signals which utilize the Vaisala WXT510 sensor. As part of the design of the WXT510, an impact sensor is utilized for the collection of rainfall observations. Prior to deployment in Oklahoma City, an array of 33 WXT510 sensors were deployed at the OKCNET intercomparison facility and compared with traditional instruments used to measure rainfall including tipping bucket rain gauges and a Geonor weighing gauge. The results of the comparison revealed that a consistent, linear bias was present between the WXT510 sensors and the traditional gauges whereby, on average, the traditional gauges measured approximately $26 \%$ less precipitation than the WXT510 sensors. In addition, the variation in recorded rainfall between WXT510 sensors was consistent with that recorded by the tipping bucket gauges. As such, a correction was developed using the WXT510 and tipping bucket data. This correction was applied to the WXT510 rainfall observations and cross-verified using the Geonor gauge data. The overall result of the study yielded a bulk correction that can be applied to rainfall observations recorded by the WXT510 to greatly improve the accumulated rainfall values. This correction is designed to improve the overall accuracy of the observations without specifically calibrating each individual WXT510 sensor and is valid regardless of rainfall intensity, length of the precipitation event, seasonal characteristics of the rainfall, or rainfall type (i.e., stratiform, convective, etc.).
\end{abstract}

\section{INTRODUCTION}

A recent study by the United Nations found that by 2025 , $80 \%$ of the world's population will live in cities [1]. Further, by 2015,26 megacities will exist worldwide with populations in excess of 10 million inhabitants [2]. At the same time, recent studies have continued to document the critical role of urban areas on local weather, climate and hydrology. As urbanization continues to increase globally, the collection of representative measurements of atmospheric conditions within urban areas continues to pose a major challenge [3].

Perhaps the most studied impact is the urban heat island (UHI) whereby temperature values within the urban core are warmer than surrounding rural areas [4]. Such conditions are enhanced during the nocturnal period with clear skies and calm wind conditions [5-8]. Additional areas of urbanatmosphere research have focused on surface humidity $[9,10]$, varying roughness and turbulence [11-14], the energy and radiation budgets [15-17], the development of the urban boundary layer [18-21], and air quality, dispersion, and pollution [22-27].

The role of precipitation and hydrological processes is also an area of emphasis for urban-atmosphere research [2830]. Because of increased impermeability within urban zones, excessive precipitation can lead to increased runoff and urban flooding. At the same time, numerous additional

*Address correspondence to this author at the Oklahoma Climatological Survey, University of Oklahoma, 120 David L. Boren Blvd., Suite 2900, Norman, OK 73072, USA; Tel: 405-325-2541; Fax: 405-325-2550;

E-mail: jbasara@ou.edu studies have identified a link between large urban areas and regions of enhanced precipitation in and around the urban zone. Thus, a need exists for real-time, research quality observations of precipitation in and around urban areas.

In the United States, the majority of real-time, continuous, research-quality atmospheric observations are not collected within the core regions of cities. In addition, much of the current understanding of the impacts of urban areas on atmospheric processes has resulted from field programs with limited intensive sampling periods [31-36]. Even so, precipitation specific networks have been deployed in urban areas such as Atlanta [37] and Denver [38] to quantify the variability of rainfall for a variety of research and public service applications.

Fully deployed in the summer of 2008 and commissioned on 1 November 2008, the Oklahoma City Micronet (OKCNET) was designed to collect real-time observations of atmospheric conditions across the metropolitan area of Oklahoma City, USA. The network of 40 stations (Fig. 1) includes 36 sites mounted on traffic signals which utilize the WXT510 sensor manufactured by Vaisala Inc. (http://www. vaisala.com) to collect observations of air temperature, humidity, wind speed, wind direction, pressure, and precipitation at an interval of one minute. The precipitation measurements represent a critical component to the goals of OKCNET, however, the WXT510 sensor utilizes technology to measure precipitation that is uncommon to most meteorological stations: an impact sensor. Thus, prior to deployment in Oklahoma City, the WXT510 sensors were deployed in a test array for a period of 15 months to evaluate the precipitation measurements versus other calibrated sensors. As such, 


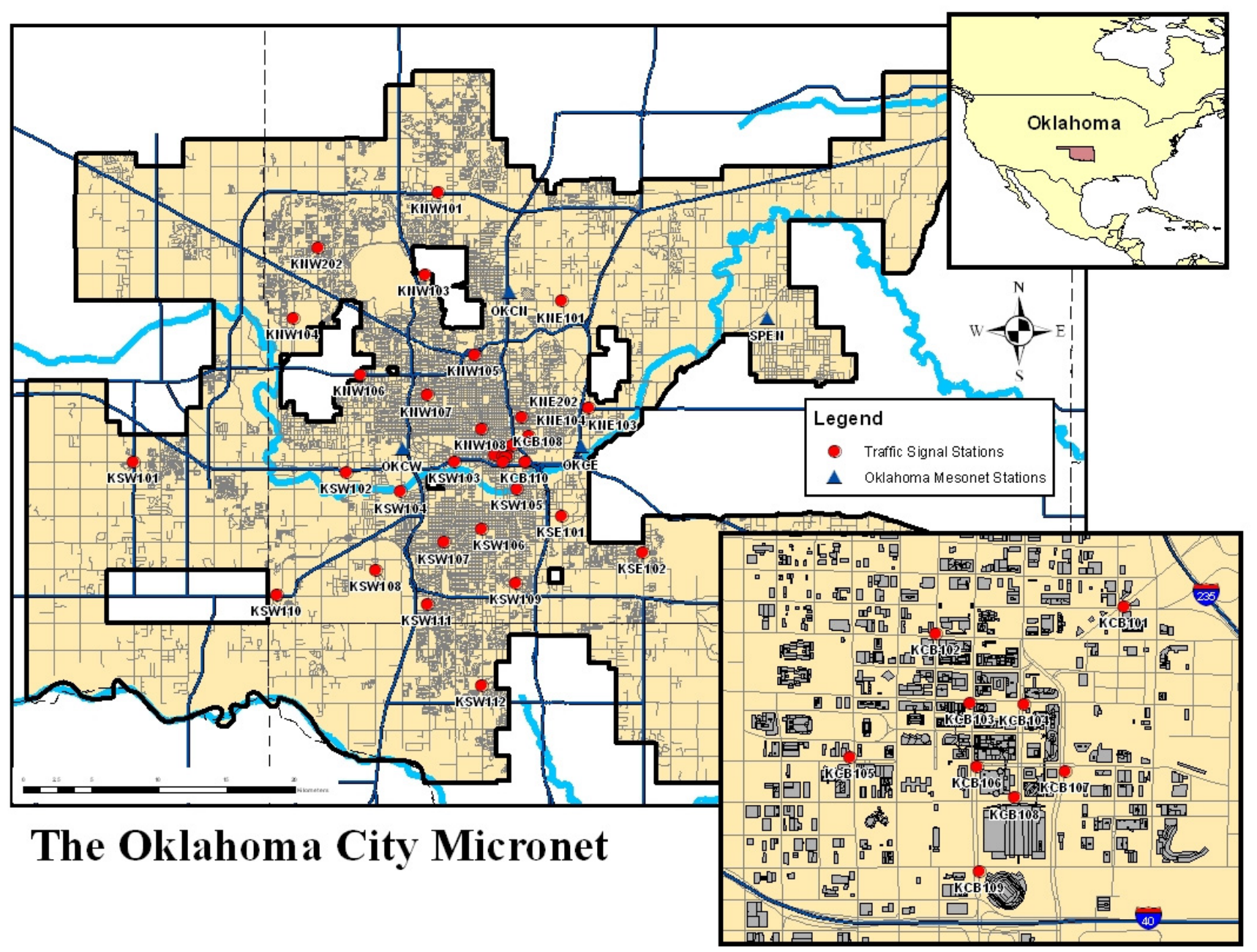

Fig. (1). The location of Oklahoma City Miconet stations. The insert in the lower right displays stations within the central business district of Oklahoma City while the insert in the upper right displays the State of Oklahoma (shaded in red) which lies in the central portion of the United States; Oklahoma City it the capitol city of Oklahoma and is located in the geographic center of the state.

this study focused on quantifying the accuracy of the WXT510 precipitation measurements and overall variability between sensors.

\section{EXPERIMENT OVERVIEW}

The Vaisala WXT510 Weather Transmitter (Fig. 2) is a compact instrument that collects observations of air temperature, relative humidity, pressure, wind speed, wind direction, and precipitation. The WXT510 requires little maintenance once deployed on account of minimal power use during data collection and the absence of moving parts. Such qualities make the WXT510 a significant candidate instrument package for use in urban areas and was chosen as the core instrument for the traffic signal stations deployed in the Oklahoma City Micronet.

The portion of the WXT510 instrument that collects precipitation measurements is referred to as the RAINCAP sensor which utilizes acoustic rain/hail impact measurement technology. Precipitation accumulation is measured as a function of the voltage signal of the hydrometeors as they impact the sensor. Each voltage signal is proportional to the volume of a specific hydrometeor which is subsequently converted to accumulated precipitation.

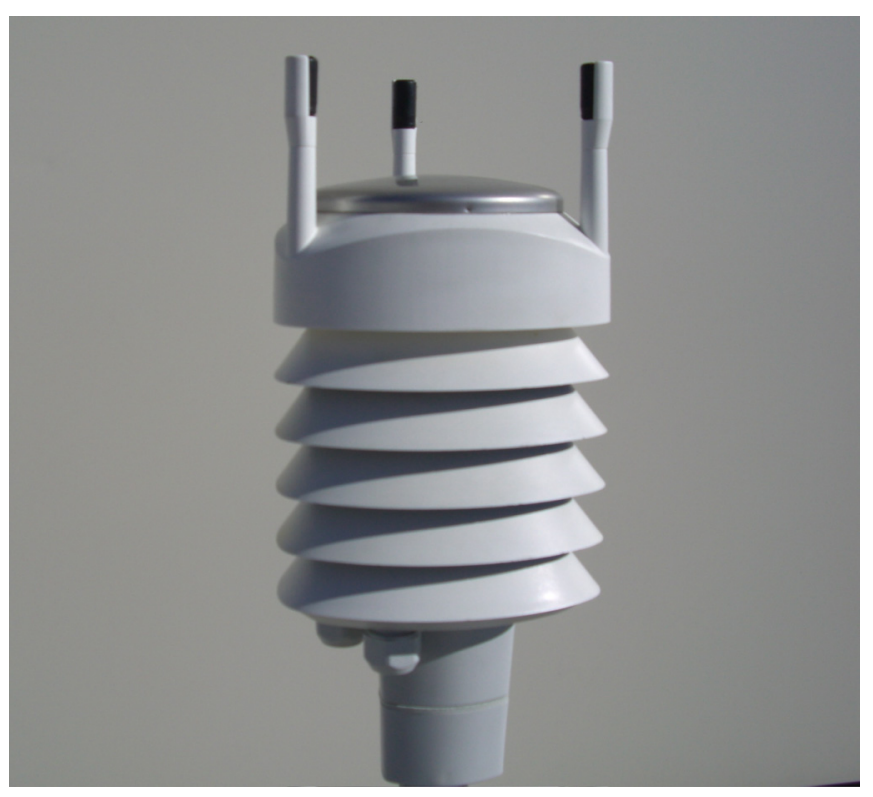

Fig. (2). A vaisala WXT510 weather transmitter.

In June 2006, the OKCNET intercomparison facility was erected in an open area in Norman, Oklahoma, USA $\left(35^{\circ} 15^{\prime}\right.$ 


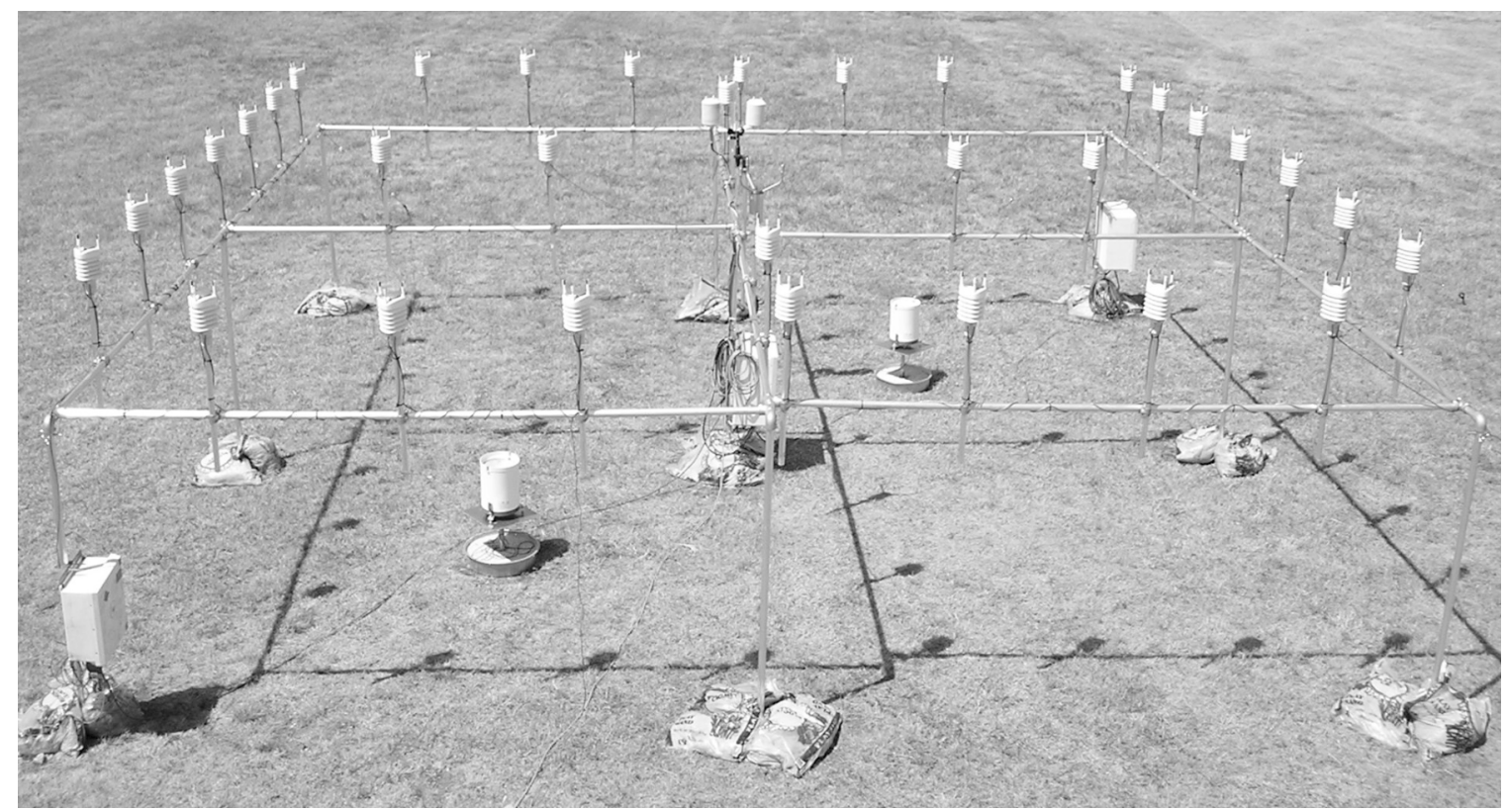

Fig. (3). A picture of the intercomparison facility for the WXT510 sensors.

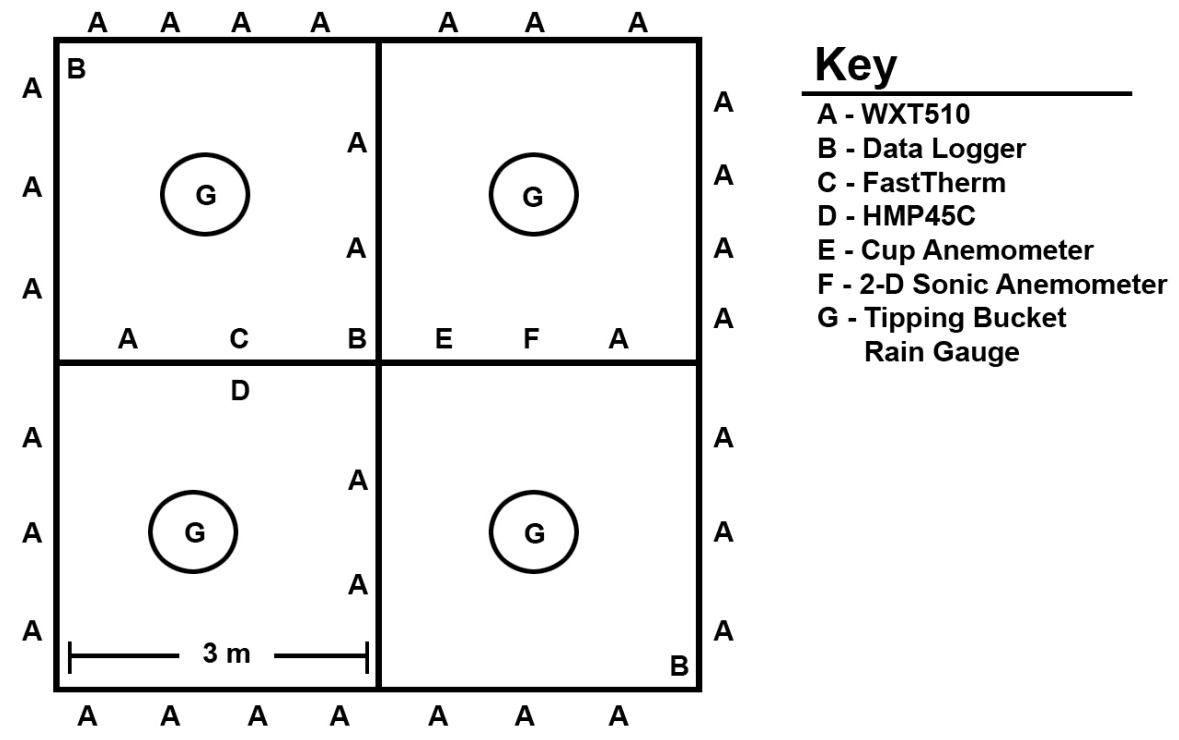

Fig. (4). A schematic diagram of the intercomparison facility for the WXT510 sensors.

$\mathrm{N} 97^{\circ} 29^{\prime} \mathrm{W}$ ) that is used to test and calibrate atmospheric instruments. The intercomparison facility was comprised of 33 WXT510 sensors and four WaterLog H-340 (http://www.waterlog.com) tipping bucket rain gauges (Figs. 3, 4). This study also utilized a number of additional rain gauges located nearby (Fig. 5). A pit-level Geonor T-200B3 (http://www.geonor.com) weighing gauge was located approximately $65 \mathrm{~m}$ from the center of the intercomparison facility. Pit-level gauges are generally used as "ground truth" for liquid precipitation measurements because wind-induced under-catch is nearly eliminated. Additionally, data from up to eight tipping bucket gauges installed nearby were used in the comparisons. These gauges consisted of: (a) five Hydrological Services TB3 (http://www.hydroserve.com.au) rain gauges and two MetOne 380 (http://www.metone.com) tipping bucket rain gauges installed in an array approximately $70 \mathrm{~m}$ from the center of the intercomparison facility and (b) a MetOne tipping bucket rain gauge installed at the Norman
Oklahoma Mesonet station [38] located approximately 140 $\mathrm{m}$ from the center of the intercomparison facility. Manufacturer supplied sensor specifications are listed in Table $\mathbf{1 .}$

From 1 July 2006 through 30 September 2007 observations of precipitation from 105 events were collected. The timeframe of each "event" was defined to encompass the time of which the first gauge recorded precipitation (regardless of sensor) until the last measured value of precipitation was recorded (regardless of sensor). On a few occasions, more than one precipitation event occurred during a day with a separation of at least 90 minutes between the last measurement of the first event and the first measurement of the second event. Of the 105 events, nine were not included in the analysis due to presence of frozen precipitation (seven events), rogue measurements during clear skies (one event), and measurement totals outside the range (100 millimeters) of the study (one event). 


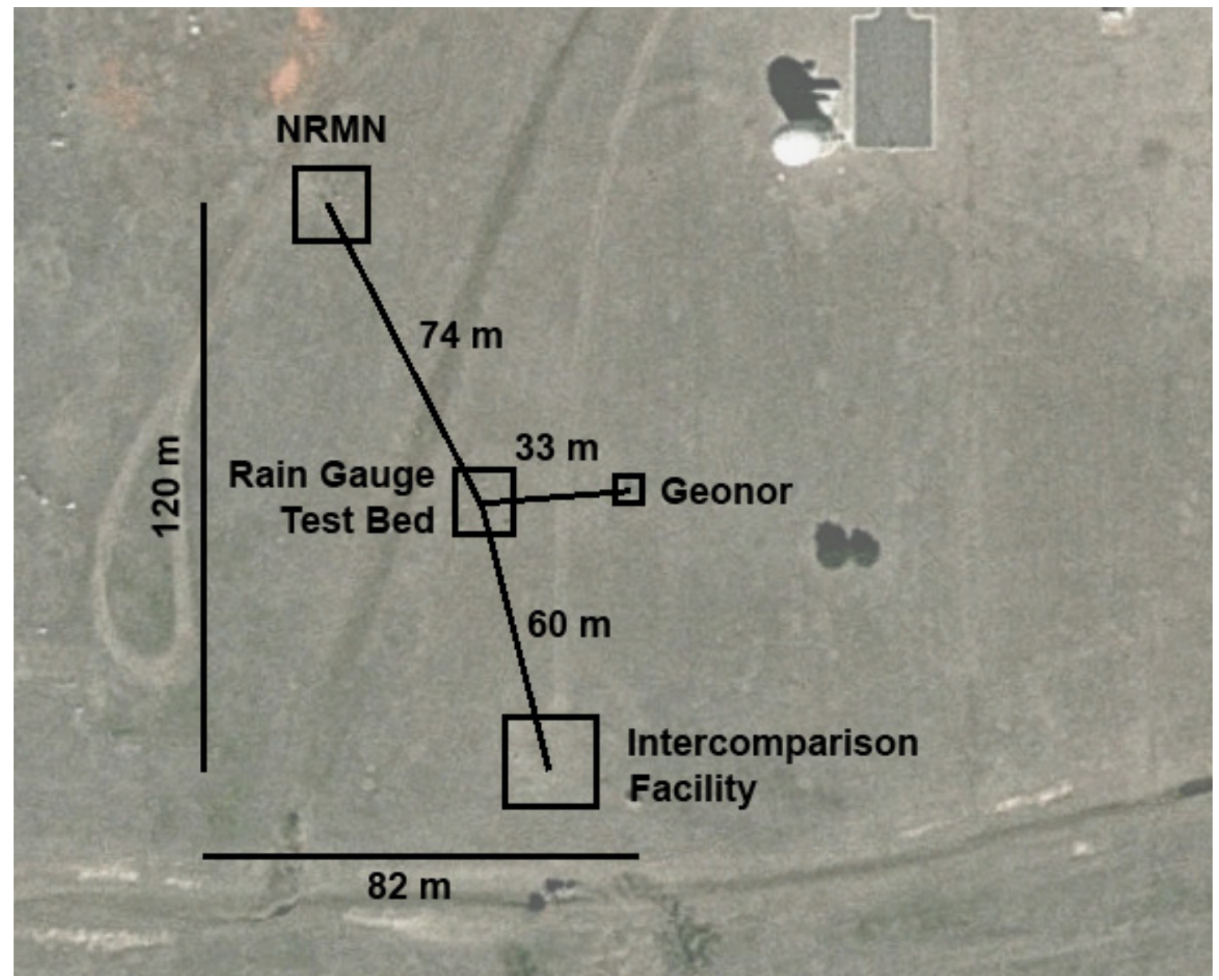

Fig. (5). An aerial map of the overall study site including the WXT510 intercomparison facility, the location of the Geonor pit gauge, the rain gauge test bed, and the Norman Mesonet site (NRMN).

Table 1. Specifications of the Various Rain Gauges Used in the Analysis

\begin{tabular}{|c|c|c|c|}
\hline Gauge & Mounting Height & Orifice Diameter & Specified Accuracy \\
\hline \hline WXT510 Impact Sensor & $1.5 \mathrm{~m}$ & $9 \mathrm{~cm} *$ & $5 \%$ \\
\hline Waterlog H-340 Tipping Bucket Gauge & $0.6 \mathrm{~m}$ & $20.32 \mathrm{~cm}$ & Not listed \\
\hline Geonor T-200B3 Weighing Gauge & $0.0 \mathrm{~m}$ & $15.96 \mathrm{~cm}$ & $0.1 \%$ \\
\hline Hydrological Services TB3 Tipping Bucket Gauge & $0.6 \mathrm{~m}$ & $20.32 \mathrm{~cm}$ & $+/-2 \%$ at 2.5 to $50 \mathrm{~cm} \mathrm{~h}^{-1}$ \\
\hline MetOne 380 Tipping Bucket Gauge & $0.6 \mathrm{~m}$ & $30.48 \mathrm{~cm}$ & $+/-0.5 \%$ at $1.27 \mathrm{~cm} \mathrm{~h}^{-1} ;$ \\
& & & \\
\hline
\end{tabular}

* Diameter of impact sensor.

During the 96 events used in the study, varying precipitation intensities and durations occurred: four events were the result of drizzle, eight events were light rain $(<1 \mathrm{~mm}), 37$ events were rain (steady precipitation with no thunder), and 47 events were convective precipitation (thunder present and/or large rainfall rates over a short period of time). Short duration (less than 1 hour) events comprised 11 of the 96 events, medium duration (1 to 4 hours) included 22 events, and 63 events spanned a duration greater than 4 hours.

Data from each sensor was quality assured via visual inspection and all tipping bucket measurements underwent standard Oklahoma Mesonet quality assurance procedures
[39]. For the 33 WXT510 sensors, any data measured by a sensor that was more than three standard deviations from the mean of all the sensors was removed from the event's statistics. The Geonor data was manually inspected to remove any suspect or incorrect data as a result of sensor malfunction or maintenance.

\section{RESULTS}

\subsection{Analysis of Precipitation Totals}

The primary objective of the study was to quantify any systematic error associated with the rainfall measurements collected by the WXT510 sensor. As such, WXT510 precipi- 
tation observations from the OKCNET intercomparison facility were compared with the tipping bucket rain gauges at the study site.

Unfortunately, precipitation measurements are subject to errors due to various physical processes and have been well documented for numerous technologies including tipping bucket rain gauges. Most notably are errors due to under catch during both very light and heavy precipitation events as well as underestimation due to wind [40-43]. The result of such errors is that, even when identical, calibrated gauges are deployed in close proximity to one another, variability in the observations can occur.

At the same time, the spatial and temporal distribution of precipitation is not uniform, even at relatively small scales. Past studies have demonstrated that rainfall can vary by as much as 5\% among above ground, unshielded tipping bucket rain gauges [44]. Further [40], found that precipitation variability in the Southern Plains averages approximately $4-5$ $\mathrm{mm}$ per month during the summer and $3-6 \mathrm{~mm}$ per month during the winter.

To account for the inherent variability of rainfall observations, mean values of precipitation were analyzed instead of specific observations from specific sensors. Thus, the mean rainfall totals from the array of WXT510 sensors $\left(\mathrm{WXT}_{\text {MEAN }}\right.$ ) for a specific event were compared with the mean rainfall totals from the local tipping bucket rain gauges (Tip MEAN).

The results of the analysis demonstrated that while the WXT $_{\text {MEAN }}$ and the Tip MEAN $_{\text {of rainfall were highly correlated }}$ $\left(\mathrm{R}^{2}\right.$ value of 0.9552$)$ a significant bias was also evident whereby the $\mathrm{WXT}_{\text {MEAN }}$ values were greater in magnitude



all bias, which included all precipitation conditions (i.e., drizzle, stratiform rain, convective rain, etc.), between the observations was linear. Thus, a simple correction was applied to the $\mathrm{WXT}_{\text {MEAN }}$ observations to improve the precipitation estimates:

$\mathrm{WXT}_{\mathrm{CORR}}=0.74 * \mathrm{WXT}_{\mathrm{RAW}}$

where, $\mathrm{WXT}_{\mathrm{CORR}}$ is the corrected WXT values and $\mathrm{WXT}_{\mathrm{RAW}}$ is the raw, measured WXT values.

Once adjusted, the corrected $\mathrm{WXT}_{\text {MEAN }}$ values were

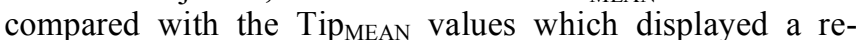
duced bias in the observations (Fig. 7). To further test the validity of the $\mathrm{WXT}_{\mathrm{CORR}}$ estimates of accumulated precipitation, the $\mathrm{WXT}_{\mathrm{CORR}}$ observations were compared with the independent precipitation totals from the Geonor rain gauge (Fig. 8). This analysis revealed that the $\mathrm{WXT}_{\mathrm{CORR}}$ values were very similar to the Geonor totals with an $\mathrm{R}^{2}$ value of 0.9522, no bias, and overall reduced error; the Geonor totals were, on average, approximately $3.5 \%$ greater than the $\mathrm{WXT}_{\mathrm{CORR}}$ values.

\subsection{Analysis of Variability}

The analysis performed in Section 3.1 provides a bulk correction that can be applied to the raw precipitation values measured by the WXT510 sensors. To determine the overall sensor-to-sensor variability of the WXT510 observations, values of standard deviation and mean absolute deviation were computed for the $\mathrm{WXT}_{\mathrm{CORR}}$ values for each precipitation event during the study period at the OKCNET intercomparison facility. In addition, similar statistics were computed to measure the variability between the tipping bucket rain gauges during the period.



Fig. (6). Raw WXT510 precipitation measurements (in millimeters) plotted versus all tipping bucket precipitation measurements. 


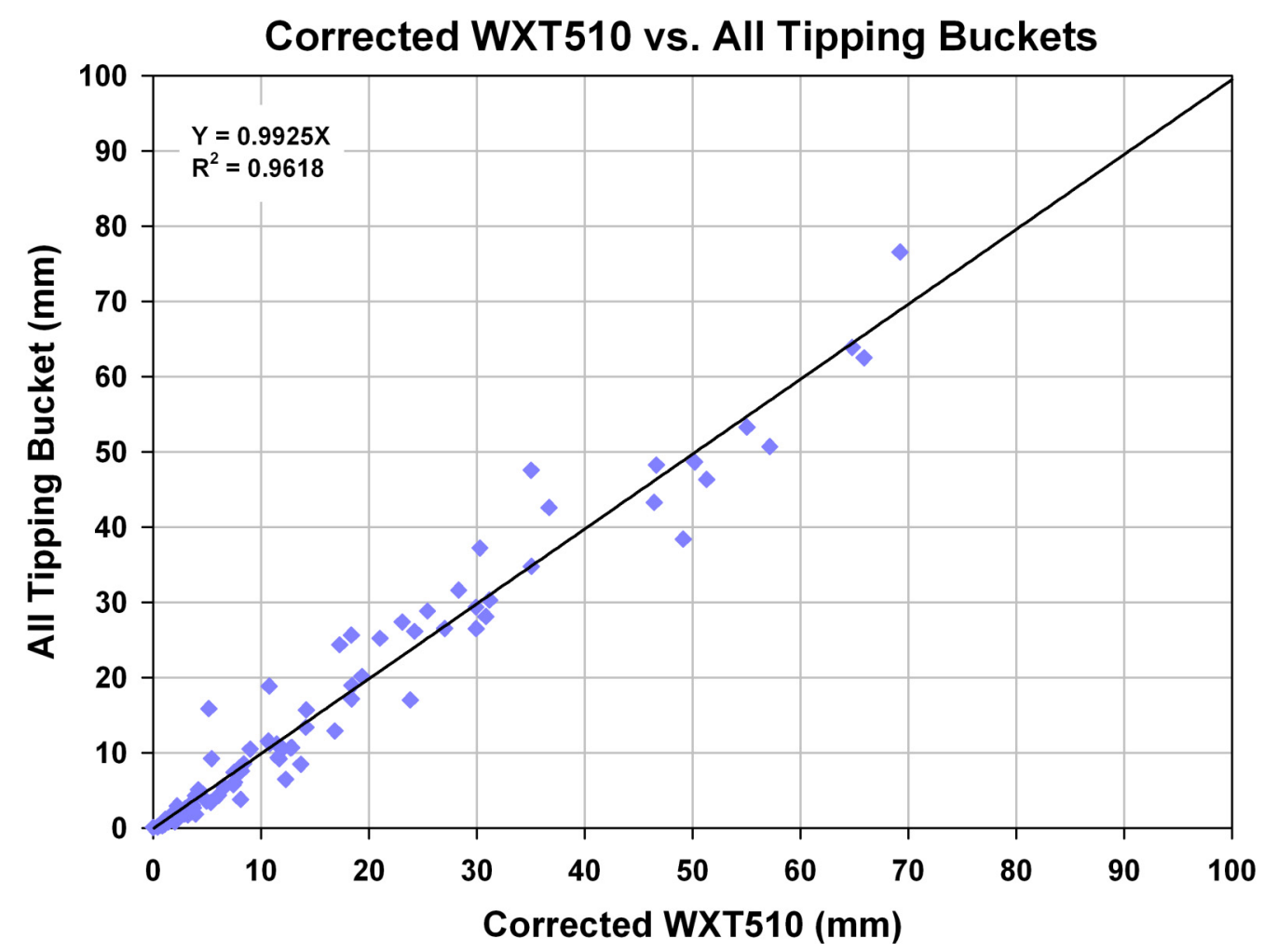

Fig. (7). Corrected WXT510 precipitation measurements (in millimeters) plotted versus all tipping bucket precipitation measurements.

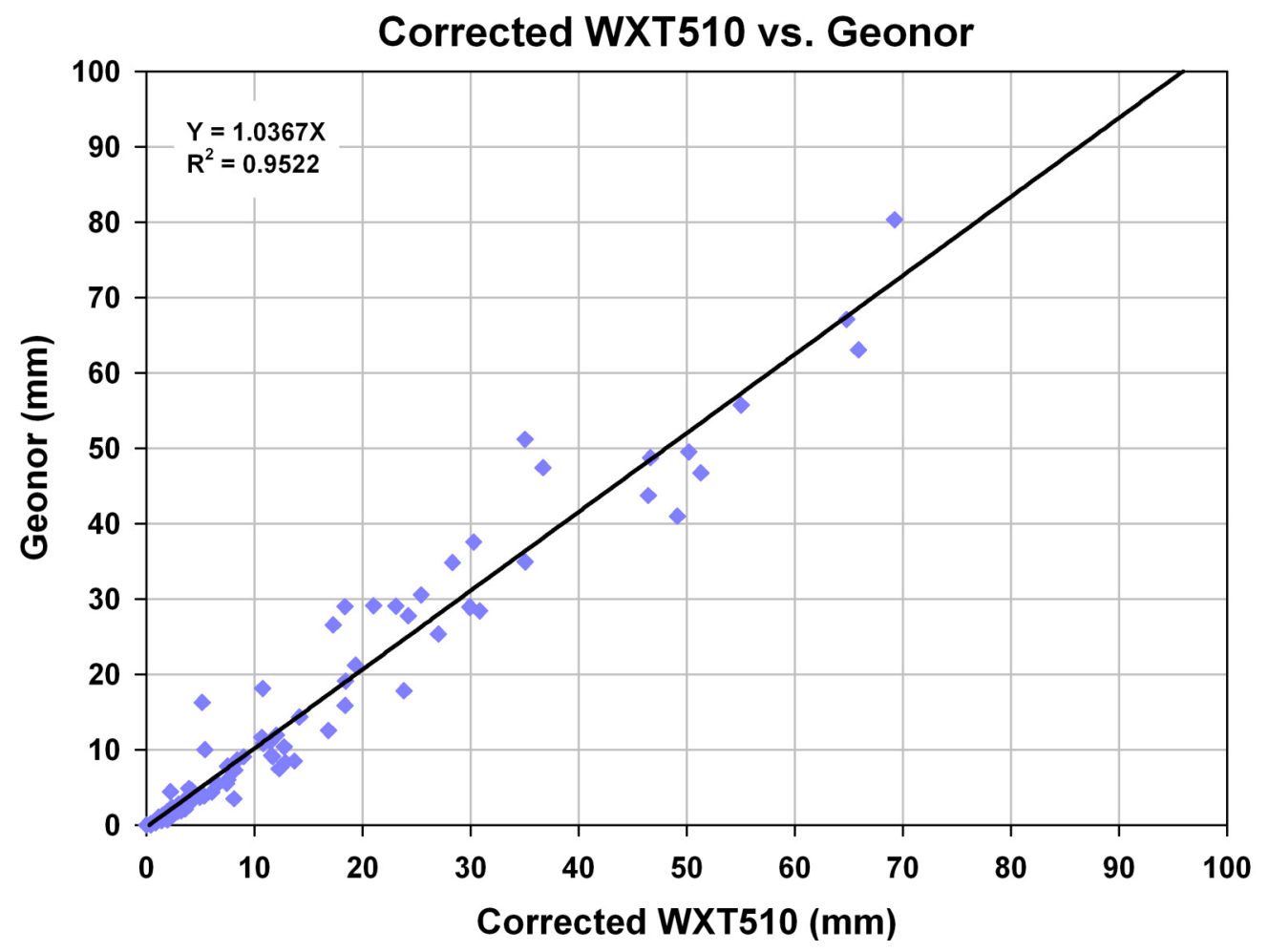

Fig. (8). Corrected WXT510 precipitation measurements (in millimeters) plotted versus the Geonor precipitation measurements.

The results of the statistical analysis are displayed in Figs. (9, 10). Overall the variability between the WXT510 sensors was limited and demonstrated a consistent, linear pattern as overall precipitation totals increased. In fact, both statistical analyses revealed that the variability between the WXT510 sensors was less than $2.1 \mathrm{~mm}$ for total precipitation events less than $30 \mathrm{~mm}$ and less than $4.0 \mathrm{~mm}$ for precipitation events between 30 and $70 \mathrm{~mm}$. In broader context, the variability between the WXT510 sensors was also very consistent with the variability displayed by the tipping bucket rain gauges. 


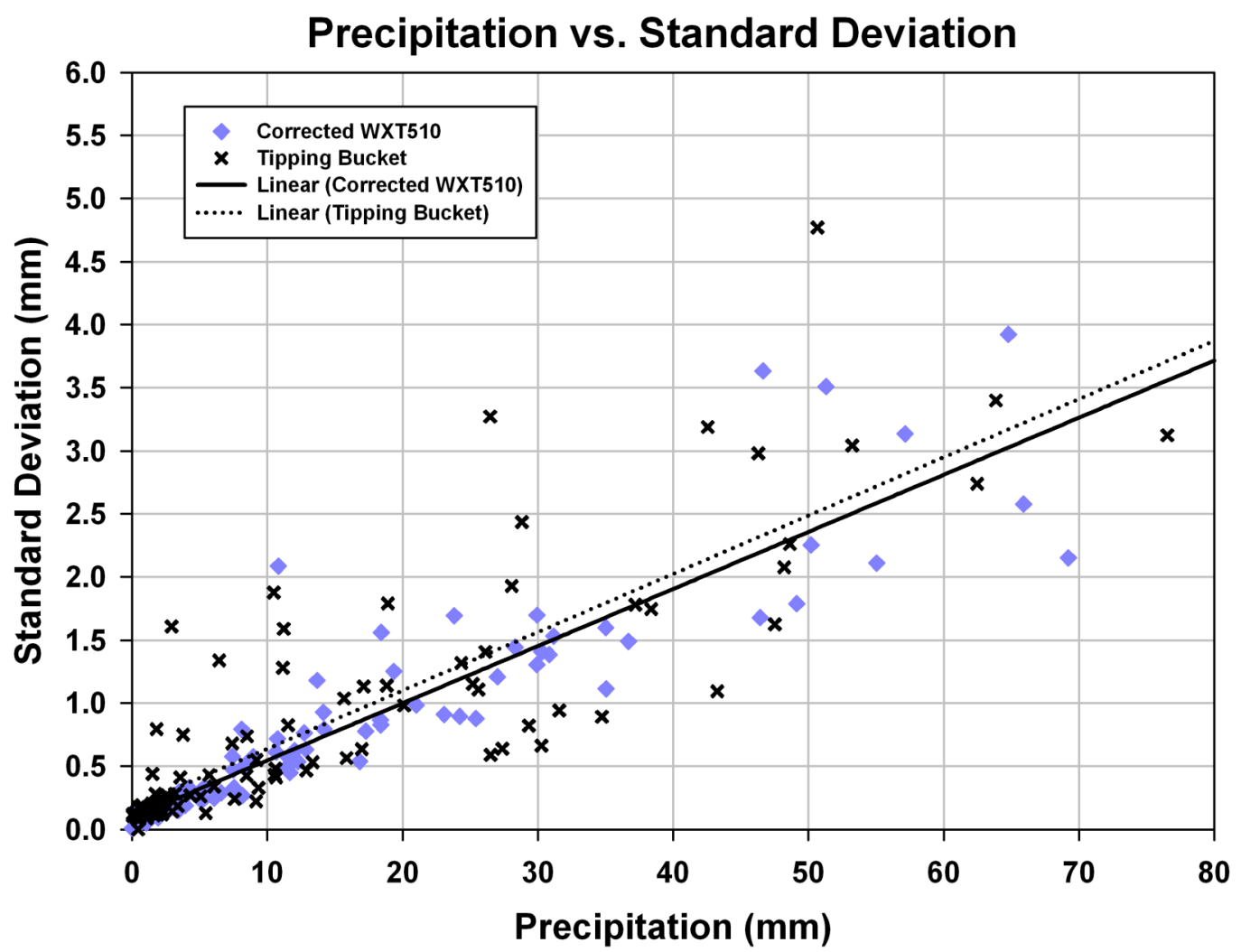

Fig. (9). The variability (using standard deviation) of corrected WXT values and tipping bucket values as a function of precipitation amount (in millimeters).

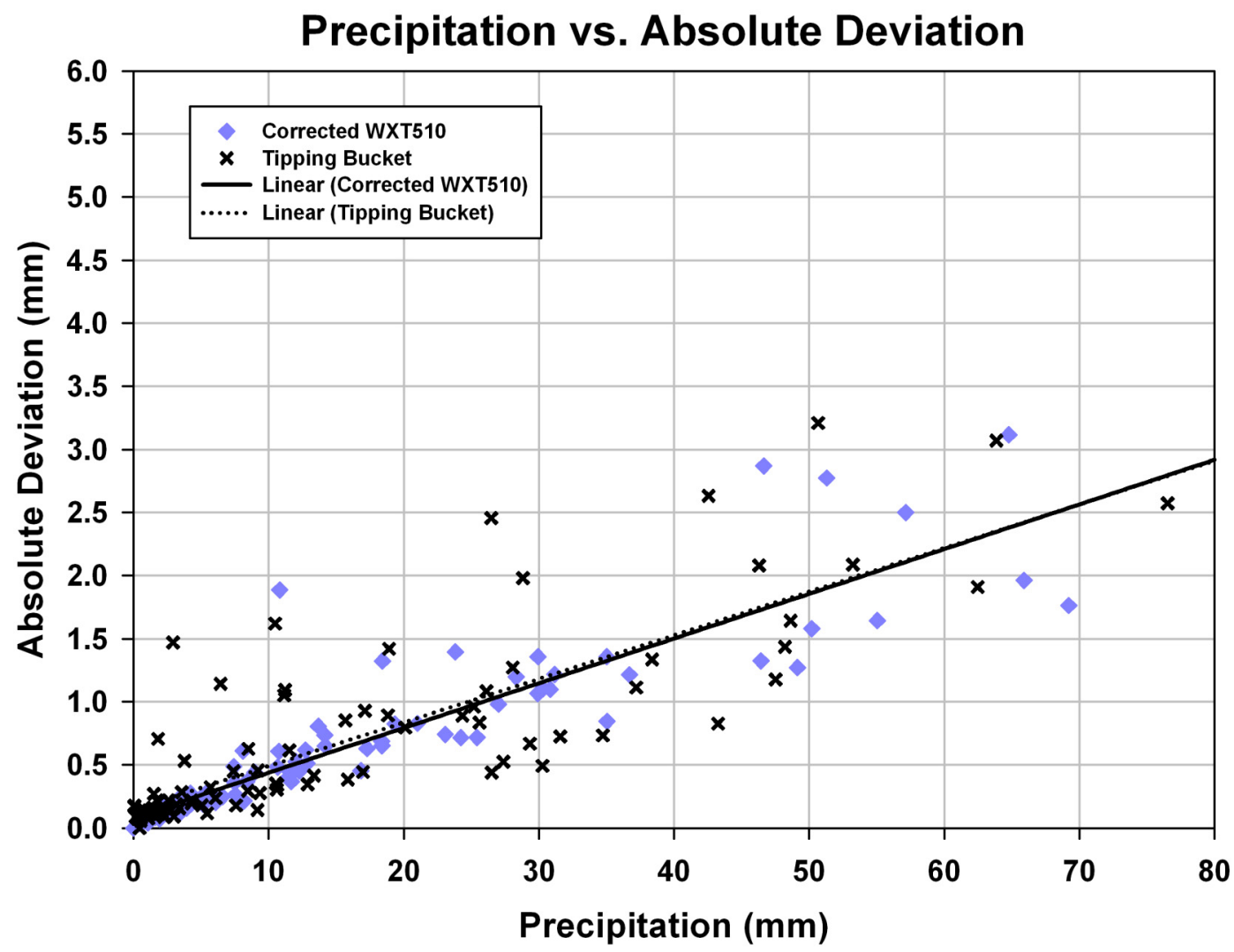

Fig. (10). The variability (using absolute deviation) of corrected WXT values and tipping bucket values as a function of precipitation amount (in millimeters). 


\section{DISCUSSION AND CONCLUSIONS}

Because the WXT510 sensor utilizes a technology to measure rainfall that is fundamentally different than traditional rainfall measurement devices, traditional methods for calibrating and evaluating sensors cannot be easily applied. As such, procedures in a controlled laboratory setting whereby a specific volume of water is passed through a rain gauge during calibration is not applicable based on the physics employed with an impact sensor. To accommodate for such circumstances, the instruments require calibration in controlled, real-world conditions versus instruments that have received thorough laboratory calibration. Unfortunately, precipitation is typically infrequent in occurrence and accurate calibration requires numerous samples. Thus, longterm records are needed to perform a thorough field analysis.

To perform an adequate assessment of the rainfall measurements collected by the WXT510 sensors for use in the Oklahoma City Micronet, this study utilized 33 units deployed at the OKCNET intercomparison facility to quantify the accuracy, systematic error, and variability of the observations. During a 15-month period spanning June 2006 through October 2007, observations were collected by the WXT510 instruments along with measurements from additional tipping bucket gauges and a Geonor gauge. The primary results of the study identified that a significant bias existed between the measurements of rainfall from the WXT510 sensors and the traditional rain gauge values (i.e., tipping buckets and Geonor). However, because the rainfall relation between the instruments was linear, a simple correction was applied using the observations collected by the tipping bucket instruments. When corrected, the rainfall values were subsequently compared with independent observations from the Geonor gauge and the results confirmed the removal of the systematic bias as well as a strong correlation across the magnitudes of the rainfall values. As such, a key finding of this study is that, regardless of rainfall intensity, length of the precipitation event, seasonal characteristics of the rainfall, or rainfall type (i.e., stratiform, convective, etc.), the correction developed as part of this research greatly improves the rainfall values produced by the RAINCAP sensor on the Vaisala WXT510 instrument.

A second critical aspect of the analysis of this study focused on quantifying the inherent variability of rainfall observations between the WXT510 sensors. The results of the analysis demonstrated that (a) the variability was a linear relationship as a function of the overall magnitude of the rainfall event and, (b) the sensor to sensor variability displayed by the WXT510 sensors was very similar to the variability between the tipping bucket rain gauges.

Because of the design of the Vaisala WXT510 sensor which yields a compact size and suite of measured variables, the instrument is a viable option for measuring atmospheric conditions in urban areas. Currently, such sensors are deployed as part of operational urban networks including the Helsinki Testbed (Helsinki, Finland) [45] and the Oklahoma City Micronet. As such, the overall results of this study are important in that they demonstrate that the rainfall measurements from the WXT510 sensor provide accurate observations with limited error once an appropriate correction is applied to the data. This correction represents a bulk relationship designed to improve the overall accuracy of the ob- servations without specifically calibrating each individual sensor prior to deployment. Unfortunately, individual calibration activities of rainfall with the WXT510 sensor are time intensive due to the need for long-term field measurements in a quasi-controlled environment without developing new laboratory procedures specifically for the WXT510 sensor. However, due to the limited variability between sensors as a function of the magnitude of the precipitation event, it is reasonable to apply the correction in a general manner to individual sensors given that the sensors perform similarly during precipitation events and that the overall rainfall bias is systematic between sensors. Even so, additional, future research should focus on the development of a simpler yet more robust method for individually calibrating each WXT510 sensor with regards to rainfall.

\section{ACKNOWLEDGEMENTS}

Funding for the Oklahoma City Micronet and support for this study was provided by (1) the State of Oklahoma via a capital bond issue to improve facilities at the University of Oklahoma, (2) the Office of the Vice President for Research at the University of Oklahoma, and (3) the Oklahoma Mesonet.

\section{REFERENCES}

[1] United Nations "World Urbanization Prospects - 2003," 2003. [Online]. Available: www.unpopulation.org.

[2] United Nations Human Settlements Program, "Human Settlemenst Basic Statisitics 1997," 1997. [Online] Available: www.unhabitat. org/unchs/english/stats/contents.htm.

[3] Duh J, Shandas V, Chang H, George L. Rates of urbanization and the resilience of air and water quality. Sci Total Environ 2008; 400 (1-3): 238-56.

[4] Bornstein RD. Observations of the urban heat island effect in New York city. J Appl Meteor 1968; 7(4): 575-82.

[5] Nkemdirim LC. A test of lapse rate/wind speed model for estimating heat island magnitude in an urban airshed. J Appl Meteor 1980; 19(6): 748-56.

[6] Kidder SQ, Essenwanger OM. The effect of clouds and wind on the difference in nocturnal cooling rates between urban and rural areas. J Appl Meteor 1995; 34 (11): 2440-8.

[7] Lu J, Arya SP. A laboratory study of the urban heat island in a calm and stably stratified environment, Part I: temperature field. J Appl Meteor 1997; 36(10): 1377-91.

[8] Basara JB, Hall PK, Schroeder A, Illston BG, Nemunaitis KL. The diurnal cycle of the urban heat island in Oklahoma City. J Geophys Res 2008; 113: D20109, doi:10.1029/2008JD010311.

[9] Richards K, Oke TR. Validation and results of a scale model of dew deposition in urban environments. Int J Climatol 2002; 22(15): 1915-33.

[10] Richards K. Observation and simulation of dew in rural and urban environments. Prog Phys Geog 2004; 28(1): 76-94.

[11] Grimmond CSB, King TS, Roth M, Oke TR. Aerodynamic roughness of urban areas derived from wind observations. Bound-Lay Meteor 1998; 89(1): 1-24.

[12] Grimmond CSB, Oke TR. Aerodynamic Properties of urban areas derived from analysis of surface form. J Appl Meteor 1999; 38(9): 1262-92.

[13] Roth M. Review of atmospheric turbulence over cities. Q J Roy Meteor Soc 2000; 126(564): 941-90.

[14] Kastner-Klein P, Fedorovich E, Rotach MW. A wind tunnel study of organised and turbulent air motions in urban street canyons. J Wind Eng Ind Aerod 2001; 89(9): 849-61.

[15] Kalanda BD, Oke TR, Spittlehouse DL. Suburban energy balance estimates for Vancouver, B.C., using the bowen ratio-energy balance approach. J Appl Meteor 1980; 19(7): 791-802.

[16] Grimmond CSB, Oke TR. Turbulent heat fluxes in urban areas: Observations and a local- scale urban meteorological parameterization scheme (LUMPS). J Appl Meteor 2002; 41(7): 792-810.

[17] Christen A, Vogt R. energy and radiation balance of a central European city urban energy balance; urban radiation balance; tur- 
bulent flux densities; eddy correlation; storage heat flux; albedo, urban-rural differences; vertical flux density divergence. Int J Climatol 2004; 24(11): 1395-422.

[18] Angell JK, Hoecker WH, Dickson CR, Pack DH. Urban influence on a strong daytime air flow as determined from tetroon flights. $\mathrm{J}$ Appl Meteor 1973; 12(6): 924-36.

[19] Cleugh HA, Grimmond CSB. Modelling regional scale surface energy exchanges and $\mathrm{Cbl}$ growth in a heterogeneous, urban-rural landscape. Bound-Lay Meteor 2001; 98(1): 1-31.

[20] Martilli A. Numerical study of urban impact on boundary layer structure: Sensitivity to wind speed, urban morphology, and rural soil moisture. J Appl Meteor 2002; 41(12): 1247-66.

[21] Nair KN, Freitas ED, Sanchez-Ccoyllo OR, et al. Dynamics of urban boundary layer over Sao Paulo associated with mesoscale processes. Meteor Atmos Phys 2004; 86(1-2): 87-98.

[22] DePaul F, Sheih C. A tracer study of dispersion in an urban street canyon. Atmos Environ 1985; 19(4): 555-9.

[23] Dabberdt WF, Hoydysh WG. Street canyon dispersion: sensitivity to block shape and entrainment. Atmos Environ 1991; 25(10): 1143-53.

[24] Kastner-Klein P, Fedorovich E, Plate EJ. Gaseous pollutant dispersion around urban-canopy elements: wind tunnel case studies. Int $\mathrm{J}$ Environ Pollut 1997; 8(3-6): 727-37.

[25] Kastner-Klein P, Plate EJ. Wind-tunnel study of concentration fields in street canyons. Atmos Environ 1999; 33(24-25): 3973-9.

[26] Ratti C, Sabatino SD, Britter R, Brown M, Caton F, Burian S. Analysis of 3-D urban databases with respect to pollution dispersion for a number of European and American cities. Water Air Soil Pollut Focus 2002; 2(5-6): 459-69.

[27] National Research Council. Tracking and Predicting the Atmospheric Dispersion of Hazardous Material Releases - Implications for Homeland Security; National Academies Press: Washington, D.C., USA 2003.

[28] Dettwiller J, Changnon SA. Possible urban effects on maximum daily rainfall at Paris, St. Louis and Chicago. J Appl Meteor 1976; 15(5): 518-9.

[29] Shepherd JM, Pierce H, Negri AJ. On rainfall modification by major urban areas: observations from space-borne radar on TRMM. J Appl Meteor 2002; 41(7): 689-701.

[30] Rozoff CM, Cotton WR, Adegoke JO. Simulation of St. Louis, Missouri, land use impacts on thunderstorms. J Appl Meteor 2003; 42(6): 716-38.
[31] Changnon SA, Huff FA, Semonin RG. METROMEX: an investigation of inadvertent weather modification. Bull Am Meteor Soc 1971; 52(10): 958-67.

[32] Lowry WP. Project METROMEX: Its history, status, and future. Bull Amer Meteor Soc 1974; 55(2): 87-8.

[33] Changnon SA, Semonin RG. Chicago area program: a major new atmospheric effort. Bull Am Meteor Soc 1978; 59(2): 153-60.

[34] Grimmond CSB, Oke TR. Comparison of heat fluxes from summertime observations in the suburbs of four North American cities. J Appl Meteor 1974; 34(4): 873-89.

[35] Mailhot J, Strapp JW, MacPherson JI, et al. The Montreal-96 experiment on regional mixing and ozone (MERMOZ): an overview and some preliminary results. Bull Am Meteor Soc 1998; 79(3): $433-42$.

[36] Allwine KJ, Shinn JH, Streit GE, Clawson KL, Brown M. Overview of URBAN 2000: A multiscale field study of dispersion through an urban environment. Bull Am Meteor Soc 2002; 83(4): 521-36.

[37] Shepherd JM, Taylor OO, Garza C. A dynamic GIS-multicriteria technique for siting the NASA-clark Atlanta urban rain gauge network. J Atmos Oceanic Technol 2004; 21(9): 1346-63.

[38] Stewart KG. Coping with flash floods: Revelations from 21 years of providing flash flood warning support in Dever, Colorado 2001.

[39] McPherson RA, Fiebrich C, Crawford KC, et al. Statewide monitoring of the mesoscale environment: a technical update on the Oklahoma mesonet. J Atmos Ocean Technol 2007; 24(3): 301-21.

[40] Legates DR, Deliberty TL. Precipitation measurement biases in the United States. Water Resour Bull 1993; 29(5): 855-61.

[41] Chang M, Flannery LA. Evaluating the accuracy of rainfall catch by three different gages. J Am Water Resour Assoc 1998; 34(3): 559-64.

[42] Duchon CE, Essenberg GR. Comparative rainfall observations from pit and above ground rain gauges with and without wind shields. Water Resour Res 2001; 37(12): 3253-63.

[43] Ciach GJ. Local random errors in tipping-bucket rain gauge measurements. J Atmos Ocean Technol 2003; 20(5): 752-9.

[44] Duchon CE. Using vibrating-wire technology for precipitation measurements. In: Michaelides SC, Ed. Precipitation: Advances in Measurement, Estimation and Prediction. Springer 2008; pp. 3358.

[45] Dabberdt W, Koistinen J, Poutiainen J, Saltikoff E, Turtiainen H. Research: the helsinki mesoscale testbed: an invitation to use a new 3-D observation network. Bull Am Meteor Soc 2005; 86(7): 906-7. 